\title{
Design of four-pole chebyshev and quasi-elliptic Ka band dielectric resonator filter using higher order mode TE01( $\delta+1)$
}

\author{
Sujesh Dutta ${ }^{1}$ and Dalveer Kaur ${ }^{2}$ \\ ${ }^{1}$ Department of Electronics and Communication Engg., IKG Punjab Technical University, Jalandhar, Punjab. India \\ ${ }^{2}$ Department of Electronics and Communication Engg., IKG Punjab Technical University, Jalandhar, Punjab. India
}

\begin{abstract}
This paper describes the development of 4-Pole Chebyshev and Quasi-Elliptic Ka Band Dielectric Resonator Filter using Higher Order Mode TE018+1. A microwave filter is a two port network used to control the frequency response at a certain point in a microwave system by providing transmission at frequencies within the passband of the filter and attenuation in the stop-band of the filter. The satellite communication industry created demand for low-mass narrow-band low-loss filters with severe specification on amplitude selectivity and phase linearity. The microwave region of the electromagnetic spectrum has certain unique properties. This enable microwave signals to propagate over long distances through the atmosphere under all the most severe weather conditions. These have both military and civilian applications, including Radar, Navigation and Wireless Communication. Microwave Filters are vital components in a huge variety of electronic systems, including cellular radio, satellite communications and radar. The design of filters uses network synthesis, with which it is possible to apply systematic procedures to work forward from specification to a final theoretical design.
\end{abstract}

\section{INTRODUCTION}

AS the Federal Communications Commission (FCC) tightens the frequency allocation bands for satellite communication services providers, the need for "brick wall" filters becomes increasingly large. Adjacent channels cause co-location interference where Provider A's frequency band is almost contiguous to Provider B's frequency band. In other words, the usability of Provider A's pass-band is degraded if the power in Provider B's pass-band is not sufficiently attenuated. Typically the pass-band frequency separations are less than a few 4 MHz (for $36 \mathrm{MHz}$ Transponder Bandwidth).

To sufficiently attenuate Provider B's pass band frequencies while aiming to preserve Provider A's pass band frequencies with minimum loss, a high quality factor filter is needed. Over the years, microwave bandpass filters have been designed in various topologies such as waveguide, combline or cavity structure. In cases where a very sharp roll off is required, transmission zeros are introduced with the use of non-adjacent resonator couplings (cross-couplings). In modern day filter design, for narrow bandwidth band-pass filters; this is often implemented with a dielectric resonator filter with crosscouplings. Dielectric resonators offer compact size, temperature stability and the high quality factor necessary for this type of design. The filter is synthesized with finite transmission zeros placed at Provider B's pass-band frequencies to attenuate unwanted emissions. A microwave dielectric resonator band-pass filter described in this paper deals with the situations mentioned above.

In 1968, S.B. Cohn implemented the first high-Q dielectric resonator band-pass filter and his exploratory studies paved the way for "brick-wall" filters. In the recent past, dielectric resonator filters have been used widely in mobile communication systems, radar and satellite due to their high Q, compact size and temperature stability [1]. They offer high selectivity in narrow bandwidth applications with low insertion loss. Dielectric resonator filters have been developed in multimode, mixed-mode and single-mode cavity applications. Despite multi-mode and mixed-mode dielectric resonator cavity filters providing low loss and smaller volume, their inferior spurious transmissions and high-cost manufacturing keeps them a design rarity.

The perfect filter would have zero insertion loss in the pass-band, infinite attenuation in the stop band, and a linear phase response (to avoid signal distortions) in the pass-band. Of course, such filters do not exist in practice, so compromises must be made; herein lies the art of filter design. The insertion loss method allows a high degree of control over the pass-band and stop-band amplitude and phase characteristics, with a systematic way to synthesize a desired response. The insertion loss method allows the performance to be improved in a straightforward manner, at the expense of a higher order filter. The order of the filter is equal to the number of reactive elements used in the filter.

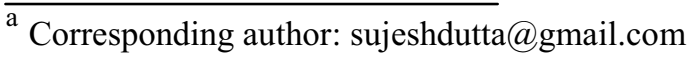


Filters designed using image parameter method consist of a cascade of simpler two-port filter sections to provide the desired cutoff frequencies and attenuation characteristics, but do not allow the specification of a frequency response over the complete operating range. Thus, although the procedure is relatively simple, the design of filters the image parameter method often must be iterated many times to achieve the desired results.

A more modern procedure, called the insertion loss method, uses network synthesis techniques to design filters with a completely specified frequency response. The design is simplified by beginning with low-pass prototypes that are normalized in terms of impedance and frequency. Transformations are then applied to convert the prototype designs to the desired frequency range [2]. The Chebyshev filter design is explained in the section II. Section III deals with the fabrication of the Quasi-elliptic filter in HFSS as well.

\section{GENERAL FILTER DESIGN}

\section{Chebyshev Response Filters}

This section contains the theory used to design the filters. These filters have a Chebyshev response. The theory used here can be found in [3] to [5].

The response of low pass filter prototype is shown in figure 1. The general procedure of calculating the design parameters with the aid of a CAD simulator is explained below.

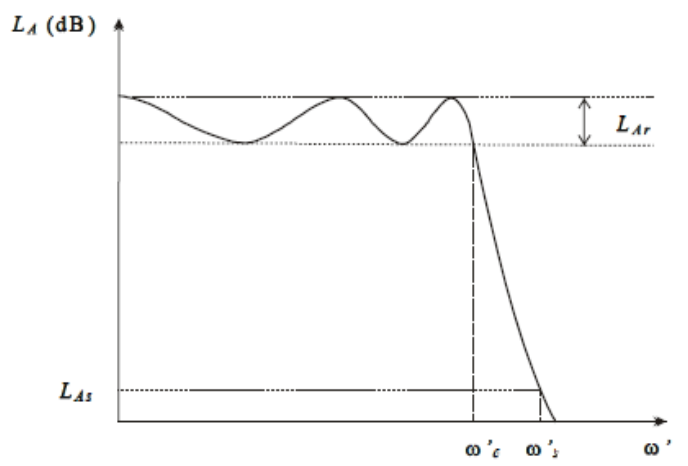

Figure 1. Chebyshev low pass prototype response.

The design specification of a Chebyshev Filter is mentioned in the Table 1.

Table 1. DESIGN SPECIFICATION OF BAND PASS CHEBYSHEV FILTER

\begin{tabular}{|c|c|c|}
\hline S. No & Parameters & Units \\
\hline 1 & Center Frequency & $\mathrm{GHz}$ \\
\hline 2 & Usable Band width & $\mathrm{MHz}$ \\
\hline 3 & $\begin{array}{c}\text { Insertion Loss at Center } \\
\text { Frequency }\end{array}$ & $\mathrm{dB}$ \\
\hline
\end{tabular}

\begin{tabular}{|c|c|c|}
\hline 4 & $\begin{array}{c}\text { Return loss input and output } \\
\text { port }\end{array}$ & $\mathrm{dB}$ \\
\hline 5 & $\begin{array}{c}\text { Band pass flatness } \\
\text { Over } 100 \% \text { band width }\end{array}$ & $\mathrm{dB}$ \\
\hline 6 & $\begin{array}{c}\text { Rejection } \\
\text { At } \pm 70 \text { MHz from CF and } \\
\text { beyond }\end{array}$ & $\mathrm{dB}$ \\
\hline 7 & Input/Output Port & -- \\
\hline
\end{tabular}

For Chebyshev low pass prototype filters having a transfer function of Chebyshev response with a pass-band ripple $\mathrm{LAr} \mathrm{dB}$ and the cutoff frequency $\Omega \mathrm{c}=1$, the element values for the two port networks may be computed using the following formulas [6]:

$$
\mathrm{g}_{\mathrm{o}}=1.0
$$

$$
g_{1}=\frac{2}{\gamma} \sin \left(\frac{\pi}{2 n}\right)
$$

$$
g_{i}=\frac{1}{g_{i-1}} \frac{4 \sin \left[\frac{(2 i-1) \pi}{2 n}\right] \sin \left[\frac{(2 i-3) \pi}{2 n}\right]}{\gamma^{2}+\sin ^{2}\left[\frac{(i-1) \pi}{n}\right]}
$$

for $\mathrm{i}=2,3, \ldots \mathrm{n}$

$$
g_{n+1}= \begin{cases}1.0 & \text { for } n \text { odd } \\ \operatorname{coth}^{2}\left(\frac{\beta}{4}\right) & \text { for } n \text { even }\end{cases}
$$

where

$$
\beta=\ln \left[\operatorname{coth}\left(\frac{L_{A r}}{17.37}\right)\right] \quad \& \quad \gamma=\sinh \left(\frac{\beta}{2 n}\right)
$$

Here for this filter pass band return loss is $26 \mathrm{~dB}$. No of poles are 4 .

So, from pass band return loss we can calculate pass band insertion loss $\left(\mathrm{L}_{\mathrm{Ar}}\right)$ and which is equal to $0.01 \mathrm{~dB}$.

From equations (1) to (5), we can have the values of $g$ as

$$
\begin{aligned}
& \mathrm{g}_{0}=1 \\
& \mathrm{~g}_{1}=0.7129 \\
& \mathrm{~g}_{2}=1.2004 \\
& \mathrm{~g}_{3}=1.3213 \\
& \mathrm{~g}_{4}=0.6476 \\
& \mathrm{~g}_{5}=1.008
\end{aligned}
$$

From the $g$ values, the coupling values $\mathrm{JN}, \mathrm{N}+1$ is obtained as: -

$$
I(\mathrm{~N}, \mathrm{~N}+1)=\frac{1}{\sqrt{\mathrm{g}(\mathrm{N}) * \mathrm{~g}(\mathrm{~N}+1)}}
$$

From equation no (6), we can calculate J coupling values as,

$$
\begin{aligned}
& \mathrm{J}_{01}=1.1755 \\
& \mathrm{~J}_{12}=1.0697
\end{aligned}
$$




$$
\begin{aligned}
& \mathrm{J}_{23}=0.7877 \\
& \mathrm{~J}_{34}=\mathrm{J}_{12} \\
& \mathrm{~J}_{45}=\mathrm{J}_{01}
\end{aligned}
$$

By putting these $\mathrm{J}$ values the circuit obtained is shown in the fig. 2 to 4 .

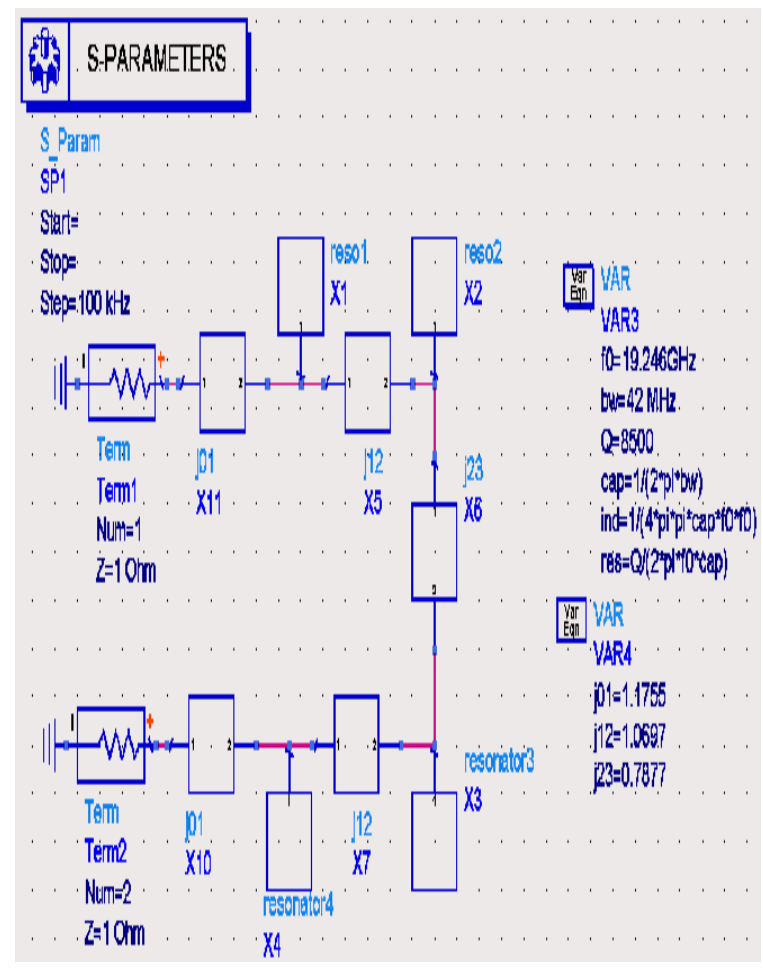

Figure 2 : Equivalent model of Band Pass filter considering admittance inverters

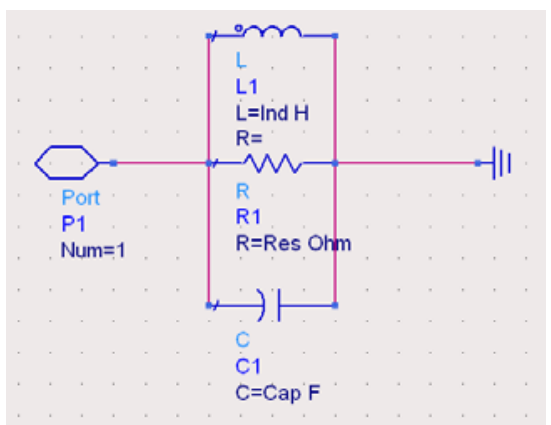

Figure 3 : Equivalent circuit of Resonator

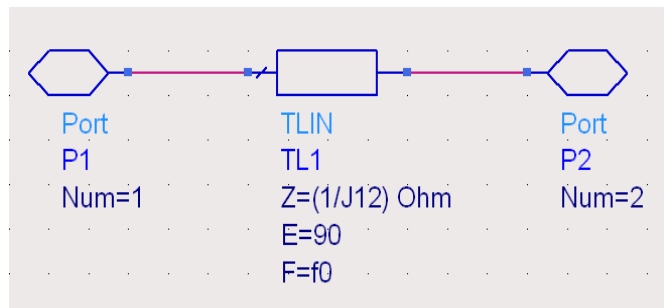

Figure 4: Equivalent circuit of Admittance Inverter

The Advantages of Chebyshev filtering function are: -

i) For same no. of poles, Chebyshev filtering function provides sharper transition from pass band to stop band than Butterworth filter. ii) It provides the optimum group delay compared to elliptic filter. It provides better band pass flatness than Butterworth [7].

The Chebyshev Response Filter exhibits equal ripple passband and maximally flat stopband. The Chebyshev and Butterworth Filters are sometimes referred to as all pole filters. The main effects of finite dissipation of bandpass filter are: -

- The mid-band insertion loss S12 is inversely proportional to the un-loaded Q of the resonators.

- The mid-band insertion loss S12 is inversely proportional to the passband bandwidth.

- The insertion loss S12 is approximately proportional to the degree of the filter.

The response in the CAD is shown in figure 5.

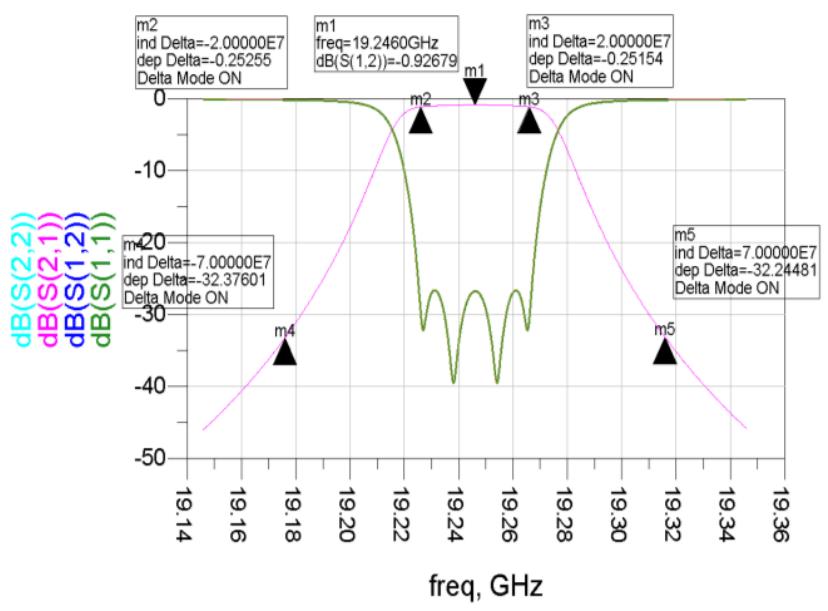

Figure 5 : Response of the filter .

\section{Quasi-Elliptic Filter}

Quasi Elliptic filters are different from the purely Elliptic filters in the sense that these are not equi-ripple in the stop band. Fully Elliptic function filters have equi-ripple passband and all the zeros of the transfer function at finite frequencies. Whereas Quasi Elliptic filters have only some of the transmission zeros at the finite frequencies. These filters are also different from the Chebychev filters as well, which has all the transmission zeros at infinity. For the same number of poles, Quasi Elliptic filters offer better rejection as compared to Chebychev filters [8].

Quasi Elliptic Filters require cross couplings for generating transmission zeros [9]. Negative crosscoupling generates transmission zeros on the imaginary axis, i.e., zero transmission at the real frequencies (@ + $2 \mathrm{j}$ ). The maximally flat and equal-ripple responses both have monotonically increasing attenuation in the stopband. In many applications, it is adequate to specify minimum stop-band attenuation, in which case a better cutoff rate can be obtained.

Following Coupling Values are obtained for realizing this filter:side.

$\mathrm{J} 01=1.1557=\mathrm{J} 45$ (Because the filter is symmetric) 
$\mathrm{J} 12=0.9963=\mathrm{J} 34$ (Because the filter is symmetric)

$\mathrm{J} 23=0.8734$

$\mathrm{J} 14=-0.2678$ (Cross coupling for realizing the transmission zeros)

Table 2. DESIGN SPECIFICATION OF BAND PASS QUASI-ELLIPTIC FILTER

\begin{tabular}{|c|c|c|c|}
\hline $\begin{array}{c}\text { Sl. } \\
\text { No }\end{array}$ & Parameters & Units & $\begin{array}{c}\text { Specification } \\
\text { s }\end{array}$ \\
\hline 1 & Center Frequency & $\mathrm{GHz}$ & 19.246 \\
\hline 2 & $\begin{array}{c}\text { Usable Band } \\
\text { width }\end{array}$ & $\mathrm{MHz}$ & 36 \\
\hline 3 & $\begin{array}{c}\text { Insertion Loss at } \\
\text { Center Frequency }\end{array}$ & $\mathrm{dB}$ & 2 \\
\hline 4 & $\begin{array}{c}\text { Return loss input } \\
\text { and output port }\end{array}$ & $\mathrm{dB}$ & 20 \\
\hline 5 & $\begin{array}{c}\text { Band pass } \\
\text { flatness } \\
\text { Over } 100 \% \text { band } \\
\text { width }\end{array}$ & $\mathrm{dB}$ & 0.5 \\
\hline 6 & $\begin{array}{c}\text { Rejection } \\
\text { At } \pm 42 \mathrm{MHz} \\
\text { from CF and } \\
\text { beyond }\end{array}$ & $\mathrm{dB}$ & 30 \\
\hline 7 & $\begin{array}{c}\text { Input/Output Port } \\
\text { Operating } \\
\text { Temperature }\end{array}$ & -- & -5 to +55 \\
\hline 8 & \begin{tabular}{c}
${ }^{\circ} \mathrm{C}$ \\
\hline
\end{tabular} & \\
\hline 14
\end{tabular}

Table II depicts the design specifications of Band-pass Quasi-Elliptic Filter. The layout of Quasi-Elliptic Filter in CAD ADS is shown in figure 6. The cross-coupling value $\mathrm{j} 14$ is used as the coupling between the resonator 1 and the resonator 4 .

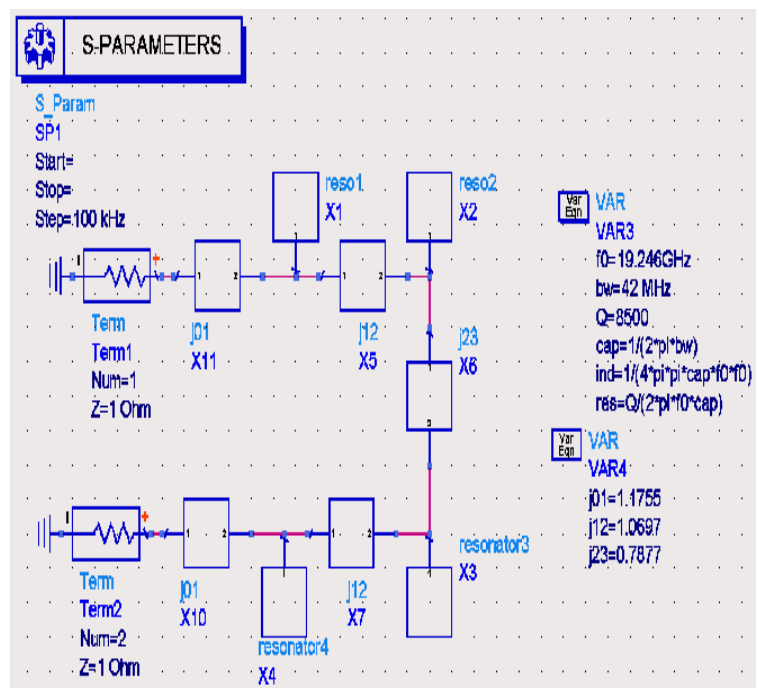

Figure 6 : ADS layout of 4-pole Quasi-Elliptic Filter.

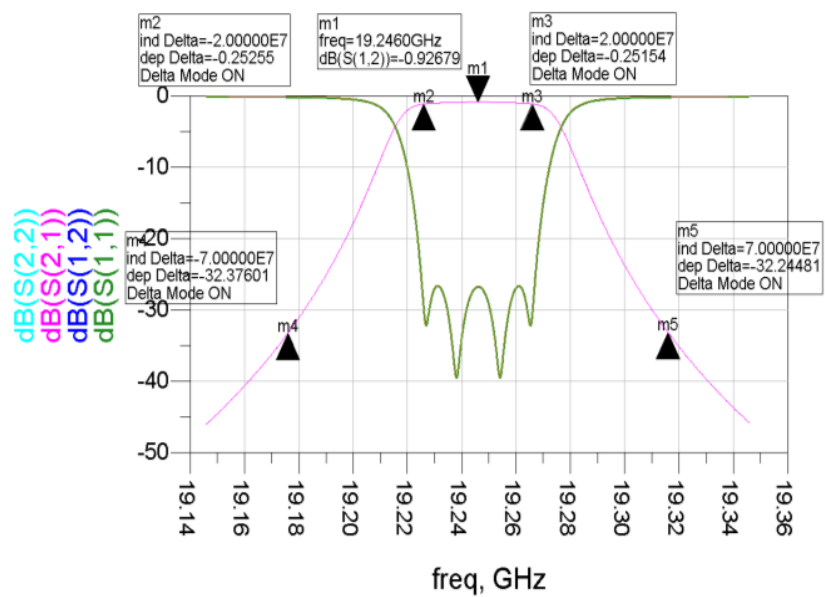

Figure 7 : Simulated response of the Filter using actual 'Q'.

The simulated response of the Filter using actual $\mathrm{Q}$ is shown in figure 7

A dielectric resonator filter uses ceramic dielectric "pucks" as resonators to form a multi-section filter. Dielectric resonators have a high dielectric constant and a low dissipation factor, which produces a high quality factor and in-turn gives a low insertion loss measurement over the filter's pass-band. Usually, dielectric resonators are inductively coupled (magnetic field) and can be mounted on a micro-strip network or inside a metallic cavity. The physical dimensions of the dielectric resonator (puck), the cavity dimensions of the puck's housing and the dielectric constant of the puck's material determine the resonant frequency, which can be approximated by.

$$
f_{G H z}=\frac{34}{I \sqrt{\varepsilon_{r}}}\left(\frac{D}{H}+3.45\right)
$$

where $\mathrm{I}$ is the inner diameter of the resonator, $\mathrm{D}$ is the outer diameter of the resonator and $\mathrm{H}$ is the height of the resonator as shown in Figure 8. At resonant frequency, the most of the energy is stored in puck

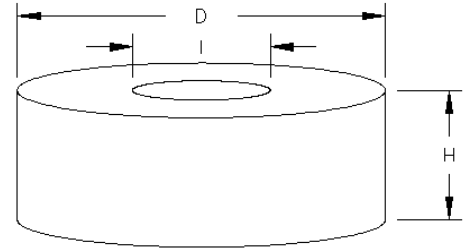

Figure 8 Unloaded Cylindrical Dielectric Resonator

The use of dielectric resonators constructed from lowloss high permittivity (20-100) temperature stable ceramics enables high-Q (up to 100 000) filters to be realized in a fraction of the volume and weight of air filled waveguide devices [10]. In HFSS, the design parameters of Microwave materials is shown in Table 3 
Table 3. DESIGN PARAMETERS IN HFSS

\begin{tabular}{|l|l|l|l|}
\hline S.No. & & Units & Size \\
\hline 1 & Cavity Size & $\mathrm{mm}$ & $7 \times 7 \times 7$ \\
\hline 2 & $\begin{array}{l}\text { Support Material } \\
\text { M6.8 }\end{array}$ & $\varepsilon$ & 6.8 \\
\hline 3 & DR Material DR_24 & $\varepsilon$ & 24 \\
\hline
\end{tabular}

When the given cavity is simulated in the CAD system at the centre frequency $10.8 \mathrm{G} \mathrm{Hz}$ in the band of $10.5 \mathrm{G} \mathrm{Hz}$ to $11 \mathrm{G} \mathrm{Hz}$, the electric field pattern are obtained having the Maximum intensity at the centre of the puck. This mode is named as TE01 $\delta$.

When the same cavity is simulated at the centre frequency $19 \mathrm{G} \mathrm{Hz}$ in the band of $18.72 \mathrm{G} \mathrm{Hz}$ to $21.72 \mathrm{G}$ $\mathrm{Hz}$, the electric field pattern has maximum intensity at the levels of 0.25 and 0.75 of the height of the puck. This is termed as TE01 $\delta+1$. The Electric Field is maximum at two locations of the puck. It signifies that more of energy is stored in the puck, thereby better Q, better selection of wanted frequency and better band rejection of unwanted frequency band.

At higher frequencies, the losses are more and the selectivity is poor, hence Q is poor. Hence we obtain the desired results at higher frequency band around $19 \mathrm{G} \mathrm{Hz}$. By employing TE01 $\delta+1$ mode at higher frequencies, we get the desired results using the materials which were

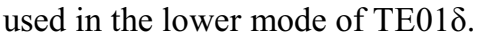

The single cavity structure was simulated in HFSS to obtain the Mode of the DR which has the maximum spurious free range, i.e. Maximum Separation. The analysis set up was run at the centre frequency $18.6 \mathrm{G}$ $\mathrm{Hz}$. The Modes obtained after the simulations is shown in Table IV.

Table 4. MODES OBTAINED AS A RESULT IN HFSS.

\begin{tabular}{|l|l|l|}
\hline S.No. & Mode & $\begin{array}{l}\text { Resonant } \\
\text { Frequency } \\
\text { GHz }\end{array}$ \\
\hline 1 & Mode 1 & 18.736082 \\
\hline 2 & Mode 2 & 18.831473 \\
\hline 3 & Mode 3 & 19.417369 \\
\hline 4 & Mode 4 & 21.624429 \\
\hline
\end{tabular}

The analysis shows that the Mode 3 is the desired mode as it has the maximum spurious free range i.e. maximum separation. At lower side19.417-18.831 $=0.59$ $\mathrm{GHz}$ and at upper side 21.624-19.417=2.21 GHz. For the realization of Quasi-elliptic filter, cross-coupling between non-adjacent cavities is made to equalize the group delay and getting finite transmission zeros[11]. The coupling may be inductive or capacitive. The inductive coupling is preferred because $96 \%$ of the electric field and $66 \%$ of magnetic field is within the DR [12][13]. The assembly of the filter in HFSS is shown in figure 8 and figure 9.

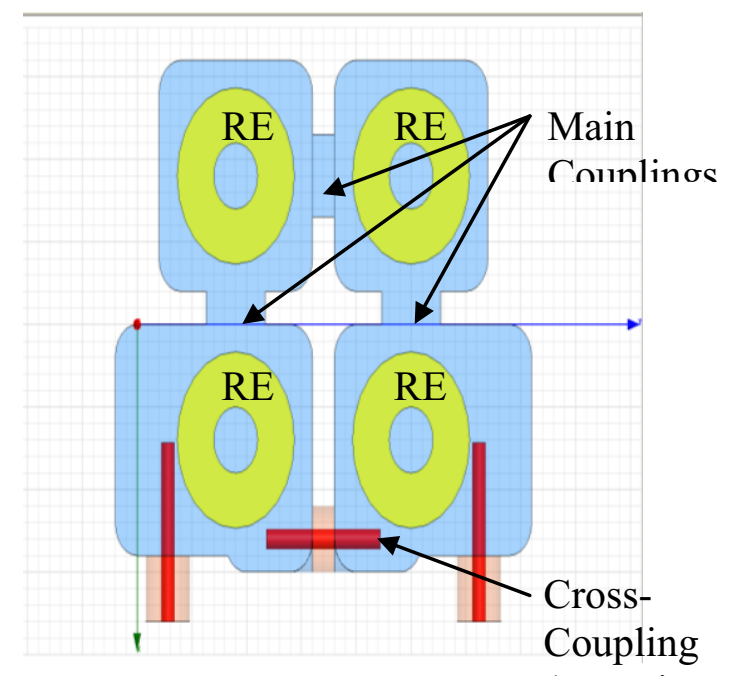

Figure 9: Complete 4-pole Quasi Elliptic filter structure

The model of the filter was simulated in the HFSS on INTEL XEON Quad-core dual CPU with 16 GB RAM and $3 \mathrm{GHz}$ processor. The final response of Quasi-elliptic filter is shown in figure 10 .

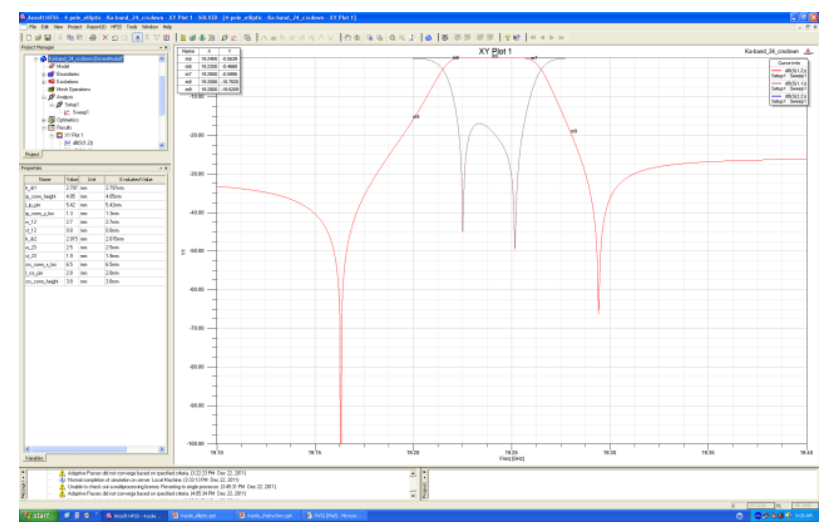

Figure 10: Final response obtained from HFSS

\section{CONCLUSIONS}

In this paper design of High ' $Q$ ' narrow-band filter in Ka band (4-Pole Chebyshev and Quasi-Elliptic) using a new higher mode has been presented. The theory of filter design using low pass prototypes and low-pass to bandpass transformations has been used as base of the concept.

\section{References}

1. Ian C. Hunter, Laurent Billonet, Bernard Jarry and Pierre Guillion, "Microwave Filters - Applications and Technology," IEEE Transactions on Microwave Theory and Techniques Vol. 50, No. 3, MAR 2002. POZAR DAVID M.: 'Microwave Engineering' (John Wiley \& Sons, India 2008) 
2. G. Matthaei, L. Young and E.M.T. Jones, "Microwave filters, impedance matching networks and coupling structures", Artech house Inc, 1964.

3. Jia-Sheng Hong and M.J. Lancaster, "Microstrip filters for RF/Microwave applications", John Wiley and Sons Inc, 2001.

4. M. Makimoto and S. Yamashita, "Microwave resonators and filters for wireless communication", Springer-Verlag Berlin Heidelberg, 2001.

5. LANCASTER M. J., HANG. JIA-SHEN G.:'Microstrip filters for RF/Microwave Applications' (John Wiley and Sons, Inc.) HUNTER I.: 'Theory and design of Microwave filters' (IEE, London, UK, 2001).

6. R. J. Cameron, "General Coupling Matrix Synthesis Methods for Chebyshev Filtering Functions," IEEE Trans. Microwave Theory Tech., vol. 47, No.4, pp. 433-442, April 1999.

7. R. J. Cameron, "Advanced Coupling Matrix Synthesis Techniques for Microwave Filters," IEEE Trans. Microwave Theory and Tech. vol. 51, No.1, Jan. 2003.

8. John B.Ness, " A Unified Approach to the Design, Measurement, and Tuning of CoupledResonator Filters," IEEE Transactions on Microwave Theory and Techniques Vol. 46, No. 4, APR 1998.

9. J. Brian Thomas, Cross Coupling in Coaxial Cavity Filters-- A Tutorial Overview," IEEE Trans. Microwave Theory and Tech.vol. 51, No. 4, APR 2003.

10. Baillargeat,D., Verdeyne, S., Galiere J, Zanchi, C., and Lapierre, L. (2005),"''Quasi-planar transversal band pass filters for $\mathrm{Ka}$ band applications", Wiley International Journal of RF and Microwave Computer-Aided Engineering, 15.56-68, doi:10.1002/mmce.2005.

11. Ruiz-Cruz, J.A., Montejo- Garai,J.R., and Zaki, K.A. (2007), "Waveguide filters with elliptic function response: Overview and results of different implementations". Wiley International Journal of RF and Microwave Computer-Aided Engineering,17.63-69,doi:10.1002/mmce.20198. 